\title{
A geospatial examination of specialist care accessibility and impact on health outcomes for patients with acute traumatic spinal cord injury in New South Wales, Australia: a population record linkage study
}

Lisa N. Sharwood ${ }^{1,2,3,4^{*}}$ (D, David Whyatt ${ }^{5}$, Bharat P. Vaikuntam ${ }^{6}$, Christiana L. Cheng ${ }^{7}$, Vanessa K. Noonan ${ }^{7}$, Anthony P. Joseph ${ }^{8,9}$, Jonathon Ball ${ }^{10}$, Ralph E. Stanford ${ }^{11}$, Mei-Ruu Kok ${ }^{5}$, Samuel R. Withers ${ }^{12}$ and James W. Middleton ${ }^{13,14}$

\begin{abstract}
Background: Timely treatment is essential for achieving optimal outcomes after traumatic spinal cord injury (TSCI), and expeditious transfer to a specialist spinal cord injury unit (SCIU) is recommended within $24 \mathrm{~h}$ from injury. Previous research in New South Wales (NSW) found only 57\% of TSCI patients were admitted to SCIU for acute post-injury care; $73 \%$ transferred within $24 \mathrm{~h}$ from injury. We evaluated pre-hospital and inter-hospital transfer practices to better understand the post-injury care pathways impact on patient outcomes and highlight areas in the health service pathway that may benefit from improvement.

Methods: This record linkage study included administrative pre-hospital (Ambulance), admissions (Admitted Patients) and costs data obtained from the Centre for Health Record Linkage, NSW. All patients aged $\geq 16$ years with incident TSCI in NSW (2013-2016) were included. We investigated impacts of geographical disparities on prehospital and inter-hospital transport decisions from injury location using geospatial methods. Outcomes assessed included time to SCIU, surgery and the impact of these variables on the experience of inpatient complications.

\footnotetext{
* Correspondence: lisa.sharwood@sydney.edu.au

'Sydney Medical School, Faculty of Medicine and Health, University of Sydney, Reserve Road, St Leonards, NSW 2065, Australia

${ }^{2}$ University of New South Wales, Faculty of Medicine and Health, NSW Black Dog Institute, Sydney, Australia

Full list of author information is available at the end of the article
}

(c) The Author(s). 2021 Open Access This article is licensed under a Creative Commons Attribution 4.0 International License, which permits use, sharing, adaptation, distribution and reproduction in any medium or format, as long as you give appropriate credit to the original author(s) and the source, provide a link to the Creative Commons licence, and indicate if changes were made. The images or other third party material in this article are included in the article's Creative Commons licence, unless indicated otherwise in a credit line to the material. If material is not included in the article's Creative Commons licence and your intended use is not permitted by statutory regulation or exceeds the permitted use, you will need to obtain permission directly from the copyright holder. To view a copy of this licence, visit http://creativecommons.org/licenses/by/4.0/ The Creative Commons Public Domain Dedication waiver (http://creativecommons.org/publicdomain/zero/1.0/) applies to the data made available in this article, unless otherwise stated in a credit line to the data. 
(Continued from previous page)

Results: Inclusion criteria identified 316 patients, geospatial analysis showed that over half $(53 \%, n=168)$ of all patients were injured within 60 min road travel of a SCIU, yet only $28.6 \%(n=48)$ were directly transferred to a SCIU. Patients were more likely to experience direct transfer to a SCIU without comorbid trauma $(p<0.01)$ but higher ICIS $\mathrm{S}(p<0.001)$, cervical injury $(p<0.01)$, and transferred by air-ambulance $(p<0.01)$. Indirect transfer to SCIU was more likely with two or more additional traumatic injuries $(p<0.01)$ or incomplete injury $(p<0.01)$. Patients not admitted to SCIU at all were older $(p=0.05)$ with lower levels of injury $(p<0.01)$. Direct transfers received earlier operative intervention (median (IQR) 12.9(7.9) hours), compared with patients transferred indirectly to SCIU (median (IQR) 19.5(18.9) hours), and had lower risk of complications (OR $3.2 \vee 1.4, p<0.001)$. Complications included pressure injury, deep vein thrombosis, urinary infection, among others.

Conclusions: Getting patients with acute TSCl patients to the right place at the right time is dependent on numerous factors; some are still being triaged directly to non-trauma services which delays specialist and surgical care and increases complication risks. The higher rates of complication following delayed transfer to a SCIU should motivate health service policy makers to investigate reasons for this practice and consent to improvement strategies. More stringent adherence to recommended guidelines would prioritise direct SCIU transfer for patients injured within 60 min radius, enabling the benefits of specialised care.

Keywords: Acute traumatic spinal cord injury, Geographic information science, Geospatial methods, SCIU, Trauma Centre, Health services pathways

\section{Background}

Traumatic spinal cord injury (TSCI) is a devastating condition with lifelong physical, psychosocial and economic impacts [1-5]. Acute post-injury phase management is time-sensitive, with rapid access to specialist care deemed essential for achieving optimal outcomes. Expeditious transfer to a specialist spinal cord injury unit (SCIU) is recommended within $24 \mathrm{~h}$ following injury [6-8], however we have previously identified low SCIU admission rates (57\%) in New South Wales (NSW), Australia [9]. Only 73\% of these were transferred within $24 \mathrm{~h}$ from injury, however geographic location of incident was not available in this former study. In recognition of international efforts to improve pre-hospital transfers where timely care is vital [10], we sought collaboration with Canadian colleagues in the improvement of these methods, adding geospatial data to map injury incident locations and hospital transfers. This study aimed to investigate geospatial influences on expeditious SCIU transfer for individuals with TSCI.

Specialist health services are often concentrated in high population density areas, though may often serve large geographical areas with substantial, distributed populations. Time and distance consequently challenge equitable access to these services for the whole population. NSW is the most populous Australian state, covering an area of $809,444 \mathrm{~km}^{2}$. NSW specialist health services include the State Spinal Cord Injury Service (SSCIS) network, providing care for approximately 5500 people living with spinal cord injury (2019) [11]. TSCI is a high acuity, resource intensive injury requiring ongoing acute and rehabilitative care; in 2017-18, there were 3888 re-hospitalisations of people living with spinal cord injury in NSW.

Epidemiological, health services studies are increasingly using geospatial methods [12-14] to better understand and target both injury prevention and post-injury care [15]. Triage optimisation using geospatial data and scenario modelling has demonstrated significantly reduced time to SCIU admission in a Canadian study [10]. Similar modelling (without geospatial data) showed that optimizing patient-care pathways can achieve significant health system cost reductions from direct in comparison with indirect admissions to SCIU [16]. Studying individuals with acute traumatic brain injury (TBI), Brown et al. [13] found significant disparity in survival rates between rural and urban areas using geospatial analysis. Specifically, in the most rural areas, TBI fatality rates were 13 deaths per 100,000 persons higher than those in the most urban area (95\% confidence interval 12.1513.86; $P<0.001$ ) [13]. A similar analysis across the NSW trauma system demonstrated a significantly higher adjusted mortality rate for patients with any traumatic injury treated in regional services compared with metropolitan major trauma services [17]. Definitive care at a Major Trauma Service (MTS) was associated with a $41 \%$ lower likelihood of death compared to definitive care at a Regional Trauma Service (RTS) (OR 0.59 95\%CI 0.35-0.97) [17].

Lack of access to specialist care services, including major trauma management [18], timely and appropriate surgical interventions within a critical time window and other factors such as increased rates of complications are likely contributing to higher mortality rates and poor 
long term outcomes for survivors. There is an indication internationally that regardless of prescribed, evidencebased pathways for trauma patients and injury locations within acceptable proximity to specialist services, some acute trauma patients are still being triaged to nontrauma services [19]. Delivery of health services must account for the fact that injuries will occur in a range of geographic locations, from urban to very remote areas. The extent to which geospatial variables impact pathways to direct SCIU admission for patients with TSCI in Australia has not been examined.

The aim of this study was to use geospatial methods to investigate the impact of geographical location on pathways and timing of admission to specialist care services for individuals sustaining acute TSCI across the state of NSW, Australia. Analyses will control for relevant variables and assess associations with patient outcomes, including time to surgery and inpatient complications.

\section{Methods}

This study used population level data combined with additional data from an observational study; the methods for the latter have been previously described [20].

\section{Setting and acute Health services}

The state of NSW, Australia, has a population of just over 8 million persons [21] and covers a geographically diverse area $>800,000 \mathrm{~km}^{2}$. Around two-thirds of the population reside in the Greater Sydney (suburban) area; the remainder in rural and very remote areas. The state government funded NSW Ambulance Service is the sole emergency medical service, transporting patients via road, fixed wing or helicopter depending on injury severity and geographic location. Road ambulances are not routinely staffed with emergency physicians, whereas some helicopter services are.

Trauma service hospitals are designated as either MTS (equivalent to Level 1 Trauma Service, accredited) or RTS (equivalent to Level 3) [22]; critically ill patients can be taken to one of six strategically located MTS or ten RTS. Approximately 200 additional non-trauma designated hospitals (district/regional/local hospitals) are situated across metropolitan and regional health districts around the state. The SSCIS comprised two specialist SCIUs, both located in metropolitan Sydney. One of these is also an MTS (categorised as SCIU for this study), the other a non-trauma designated hospital; both providing specialist spinal surgical services for TSCI. Hospitals were categorized as trauma hospitals (MTS or RTS), specialist hospitals (SCIU) or non-trauma hospitals (district/local) for the analysis.

Being suspected of having TSCI or evidence of TSCI meets major trauma criteria under the NSW state-wide pre-hospital triage criteria applies; whereby 'patients meeting major trauma criteria should be transported to the highest level Trauma Centre located within a 60-min driving radius, which may include bypassing closer nontrauma hospitals' [23]. Recommendation from the SSCIS was that once medically stable, patients with TSCI should be transferred to an SCIU within $24 \mathrm{~h}$ from injury [24].

\section{Population-level record linkage}

The NSW Admitted Patient Data Collection (APDChttps://www.cherel.org.au/data-dictionaries) was used to identify and extract TSCI patient records from all separations/discharges from NSW public hospitals, based on specific TSCI-related International Classification of Diseases, 10th version, Australian Modification (ICD-10AM) diagnosis codes [25]. Probabilistic data linkage was undertaken by the NSW Centre for Health Record Linkage, linking all patients where a TSCI code was either a principal or additional diagnosis, for any separation within the APDC. Included patients were aged 16 years or more, injured between 1 June 2013-30 June 2016, admitted to a NSW hospital and diagnosed as having TSCI using ICD-10 AM diagnostic codes [26]. Excluded were those with missing GIS data for these analyses. The first hospital episode and all contiguous care episodes, including nested/non-nested transfers, was deemed the 'index admission'.

TSCI case records were linked with Emergency Department and NSW Ambulance data. All datasets and variables included are detailed in Appendix 1.

\section{Outcome variables}

Primary outcome was triage pattern to SCIU (direct or indirect admission vs no admission) for acute incident TSCI patients. Direct admissions included those first transferred to SCIUs, indirect admissions were those transferred to SCIU hospitals from all non-SCIU hospitals. The definitive hospital was defined as the final hospital where the patient received their acute care, prior to either rehabilitation admission, discharge home or death, indicated by acute care-type and separation/discharge destination.

Secondary outcomes considered included time to surgery (for operated patients) and incidence of inpatient complications, adjusted for relevant predictor variables including triage pattern to SCIU. Inpatient complications included pressure injuries, urinary tract infections, respiratory infections, deep vein thrombosis, pulmonary embolus and others.

\section{Geospatial mapping}

Python language was used to conduct geospatial analyses, interacting with Google Distance Matrix 
Application Programming Interfaces (API) to calculate on-road travel distances and times relative to hospitals/ SCIUs using injury location GIS co-ordinates. Travel duration was classified as $<60 \mathrm{~min}$ or $>60 \mathrm{~min}$ from SCIU, and/or MTS from injury location, calculated for each patient. Population dispersement data (ABS) [21] enabled risk of disease mapping per unit-head of population over the study time-period according to Statistical Area (SA) boundaries. Population sizes for different SAs for the years 2012-2015 were calculated by linear interpolation using the 2011 and 2016 populations. Crude rates/100,000 person-years were calculated, and due to the sample size, SA3 determined the most stable representation, using person-years between 1st June 2013-30th June 2016 (Fig. 1).

\section{Statistical analysis}

Descriptive analysis included continuous variables summarised as means (standard deviations) and medians (interquartile range); categorical variables as percentages. Statistically significant differences $(<0.05)$ between groups were tested using t-tests, Wilcoxon Rank Sum or chi-square tests. Multinomial logistic regression modelling examined associations between predictor variables and direct/indirect/no admission to SCIU. Age, gender, injury mechanism, transport mode, presence of multitrauma, co-morbidity (CCI), geographic distance from incident location relative to SCIU hospital, travel time to SCIU, and injury severity (ICISS score) were included in the regression analysis for the entire study population. Admission times to 'definitive hospitals' were used from variables denoting the first admission time to the final (definitive) hospital for the acute care stay. For those patients not transferred, this was also the first hospital to which they were admitted. A multinomial logistic regression model [27] was assessed using Relative Risk Ratios (RRR), obtained by exponentiating the multinomial logit coefficients, $\mathrm{e}^{\text {coef }}$. Modelling used the category 'Direct to SCIU' as the referent group; the RRR for the groups 'Indirect to SCIU' and 'No SCIU' indicating risks relative to this referent group. STATA-IC.v.16 [28] was used for all analyses.

The NSW Population and Health Services Research Ethics Committee (Cancer Institute NSW) approved this project (AU RED Reference: HREC/16/CIPHS/19; Cancer Institute NSW reference number: 2016/07/647).

\section{Results}

\section{Demographic and injury profile}

During the study period, 534 patients with acute incident TSCI were identified across NSW; 316 (59\%) had GIS data for inclusion in geospatial analysis. Injury mechanisms were commonly falls $(n=149,47.2 \%)$ and transport crashes $(n=99,31.3 \%)$, with $53 \%(n=168)$ sustaining multiple trauma. Over one-third of patients $(n=$ 126, 39.9\%) had higher injury severity scores (ICISS< 0.83 ) [29]; the median (IQR) ICISS score was 0.839 (0.137) (Table 1); over half of all patients sustained a cervical level injury ( $n=170,53.8 \%)$.

Table 1 compares baseline demographic and injury epidemiology profile for patients admitted directly, indirectly or not at all to SCIU. Patients were more likely to experience direct transfer to a SCIU without comorbid trauma $(p<0.01)$ but higher ICISS $(p<0.001)$, cervical injury $(p<0.01)$, and transferred by air-ambulance $(p<$ $0.01)$. Indirect transfer to SCIU was more likely with two or more additional traumatic injuries $(p<0.01)$ or incomplete injury $(p<0.01)$. Patients not admitted to SCIU
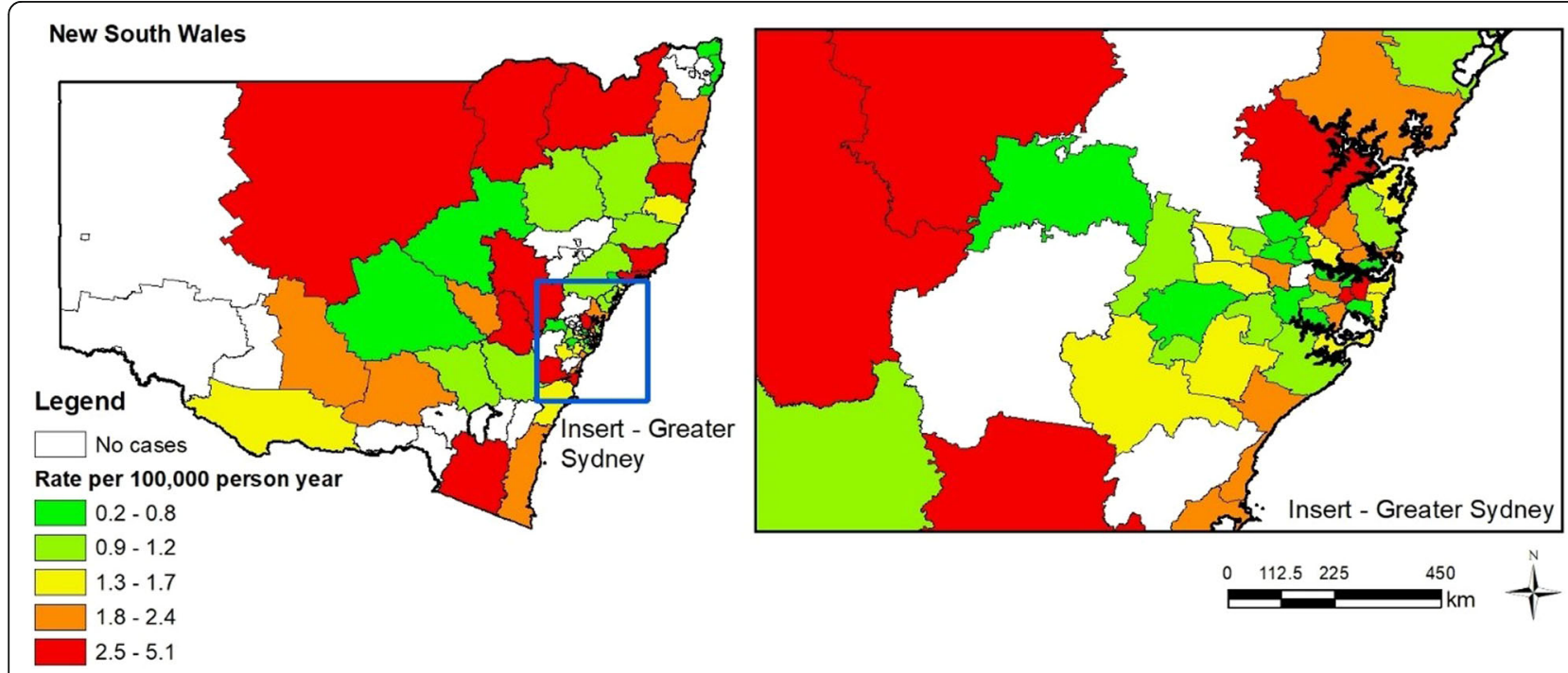

Fig. 1 Crude incidence rate per 100,000 person years by SA3 
Table 1 Comparing patients with TSCI admitted directly or indirectly to SCIU, or not at all

\begin{tabular}{|c|c|c|c|c|c|}
\hline Variable & $\begin{array}{l}\text { Direct admit to SCIU ( } n=85 \text {, } \\
26.9 \%) \\
n(\%)\end{array}$ & $\begin{array}{l}\text { Indirect admit to SCIU }(n=108 \text {, } \\
34.2 \%) \\
n(\%)\end{array}$ & $\begin{array}{l}\text { No acute admit to SCIU }(n= \\
123,38.9 \%) \\
n(\%)\end{array}$ & $\begin{array}{l}\text { Total }(n= \\
316) \\
\mathrm{n}(\%)\end{array}$ & $\begin{array}{l}p- \\
\text { value }\end{array}$ \\
\hline $\begin{array}{l}\text { Age years (median } \\
\text { (IQR)) }\end{array}$ & $57.7(28.9)$ & $52.7(37.1)$ & $60.6(38.1)$ & $56.5(36.3)$ & 0.05 \\
\hline $16-30$ & $17(20)$ & $27(25)$ & $18(14.6)$ & $62(19.6)$ & \\
\hline $31-45$ & $12(14.1)$ & $20(18.5)$ & $17(13.8)$ & $49(15.5)$ & \\
\hline $46-60$ & $22(25.9)$ & $23(21.3)$ & $28(22.8)$ & $73(23.1)$ & \\
\hline $61-75$ & $20(23.5)$ & $24(22.2)$ & $22(17.9)$ & $66(20.9)$ & \\
\hline $76+$ & $14(16.5)$ & $14(12.9)$ & $38(30.9)$ & $66(20.9)$ & \\
\hline Sex & & & & & 0.10 \\
\hline Female & $16(18.8)$ & $22(20.4)$ & $37(30.1)$ & $75(23.7)$ & \\
\hline Male & $69(81.2)$ & 86 (79.6) & $86(69.9)$ & $241(76.3)$ & \\
\hline Injury mechanism & & & & & 0.15 \\
\hline Fall & $43(50.6)$ & $45(41.7)$ & $61(49.6)$ & $149(47.2)$ & \\
\hline Transport & $32(37.6)$ & $35(32.4)$ & $32(26.0)$ & $99(31.3)$ & \\
\hline Self-harm/Assault & $1(1.2)$ & $8(7.4)$ & $7(5.7)$ & $16(5.1)$ & \\
\hline Other $^{a}$ & $9(10.6)$ & $20(18.5)$ & $23(18.7)$ & $52(16.5)$ & \\
\hline Incident GPS & & & & & 0.74 \\
\hline $\begin{array}{l}\leq 60 \min \text { to } \\
\text { SCIU }\end{array}$ & $48(56.4)$ & $55(50.9)$ & $65(52.8)$ & $168(53.2)$ & \\
\hline$>60 \mathrm{~min}$ to $\mathrm{SCIU}$ & $37(43.5)$ & $53(49.1)$ & $58(47.1)$ & $148(46.8)$ & \\
\hline SEIFA Quintiles ${ }^{b}$ & & & & & 0.002 \\
\hline 1 (lowest) & $8(9.4)$ & $21(19.4)$ & $15(12.2)$ & $44(13.2)$ & \\
\hline 2 & $14(16.5)$ & $24(22.2)$ & $29(23.6)$ & $67(21.2)$ & \\
\hline 3 & $11(12.9)$ & $23(21.3)$ & $37(30.1)$ & $71(22.5)$ & \\
\hline 4 & 15 (17.6) & $11(10.2)$ & $17(13.8)$ & $43(13.6)$ & \\
\hline 5 (highest) & $35(41.2)$ & $28(25.9)$ & $20(16.3)$ & $83(26.3)$ & \\
\hline unknown & $2(2.3)$ & $1(0.9)$ & $5(4.1)$ & $8(2.5)$ & \\
\hline Charlson (CCI) & & & & & 0.84 \\
\hline 0 & 60 (70.6) & 77 (71.3) & $82(66.7)$ & 219 (69.3) & \\
\hline 1 & $14(16.5)$ & $14(12.9)$ & $19(15.4)$ & 47 (14.9) & \\
\hline $2+$ & $11(12.9)$ & $17(15.7)$ & $22(17.9)$ & $50(15.8)$ & \\
\hline Multiple Trauma & & & & & 0.003 \\
\hline No & 33 (38.8) & $45(41.7)$ & $70(56.9)$ & $148(46.8)$ & \\
\hline 1 other injury & $29(34.1)$ & $20(18.5)$ & $23(18.7)$ & $72(22.8)$ & \\
\hline $\begin{array}{l}\geq 2 \text { other } \\
\text { injuries }\end{array}$ & $23(27.1)$ & $43(39.8)$ & $30(24.4)$ & $96(30.4)$ & \\
\hline ICISS Score & & & & & $<0.001$ \\
\hline $\begin{array}{l}<0.7 \text { (Most } \\
\text { severe) }\end{array}$ & $9(10.6)$ & $5(4.6)$ & $11(8.9)$ & $25(7.9)$ & \\
\hline 0.7 to $<0.83$ & $48(56.5)$ & $26(24.1)$ & $27(21.9)$ & 101 (31.9) & \\
\hline 0.83 to $<0.89$ & $17(20)$ & $29(26.8)$ & $23(18.7)$ & $69(21.8)$ & \\
\hline 0.89 to $<0.95$ & $8(9.4)$ & $21(19.4)$ & 29 (23.6) & $58(18.4)$ & \\
\hline 0.95 to 1.00 & $3(3.5)$ & $27(25)$ & $33(26.8)$ & $63(19.9)$ & \\
\hline Highest Level of & & & & & $<0.001$ \\
\hline
\end{tabular}


Table 1 Comparing patients with TSCI admitted directly or indirectly to SCIU, or not at all (Continued)

\begin{tabular}{|c|c|c|c|c|c|}
\hline \multirow[t]{2}{*}{ Variable } & $\begin{array}{l}\text { Direct admit to SCIU ( } n=85 \text {, } \\
26.9 \%)\end{array}$ & $\begin{array}{l}\text { Indirect admit to SCIU ( } n=108 \text {, } \\
34.2 \%)\end{array}$ & $\begin{array}{l}\text { No acute admit to SCIU ( } n= \\
123,38.9 \%)\end{array}$ & $\begin{array}{l}\text { Total }(n= \\
316)\end{array}$ & $\begin{array}{l}p \text { - } \\
\text { value }\end{array}$ \\
\hline & n (\%) & n (\%) & n (\%) & n (\%) & \\
\hline Cervical & $54(63.5)$ & $66(61.1)$ & $50(40.6)$ & $170(53.8)$ & \\
\hline Thoracic & $22(25.9)$ & $27(25)$ & 34 (27.6) & $83(26.3)$ & \\
\hline Lumbar & $9(10.6)$ & 15 (13.9) & 39 (31.7) & $63(19.9)$ & \\
\hline Extent of Injury & & & & & $<0.001$ \\
\hline Complete & $24(28.2)$ & $23(21.3)$ & $5(4.1)$ & $52(16.5)$ & \\
\hline Incomplete & $43(50.6)$ & $57(52.8)$ & 39 (31.7) & $139(43.9)$ & \\
\hline $\begin{array}{l}\text { Conus /cauda } \\
\text { equina }\end{array}$ & $11(12.9)$ & $17(15.7)$ & 38 (30.9) & $66(20.9)$ & \\
\hline Unspecified & $7(8.2)$ & $11(10.2)$ & $41(33.3)$ & $59(18.7)$ & \\
\hline Mode of Arrival & & & & & $<0.001$ \\
\hline Ambulance & $56(65.9)$ & $99(91.7)$ & $115(93.5)$ & $270(85.4)$ & \\
\hline Air ambulance & $18(21.2)$ & $5(4.6)$ & $3(2.4)$ & $26(8.2)$ & \\
\hline Others & $11(12.9)$ & $4(3.7)$ & $5(4.1)$ & $20(6.3)$ & \\
\hline
\end{tabular}

${ }^{a}$ Other included diving, horse-related incidents or not specified

${ }^{\mathrm{b}}$ SEIFA - Socio-Economic Indexes for Areas [30]

at all were older $(p=0.05)$ with lower levels of injury $(p<0.01)$.

\section{Case rates across the state of NSW}

GIS location of all cases were mapped, and crude rates calculated per 100,000 person-years (Fig. 1). Plotting case distribution per SA boundary SA3 was selected as the most stable representation.

\section{Travel times from incident location}

Around one quarter of study patients $(n=85,26.9 \%)$ were directly admitted to SCIU from the injury scene, 170 (53.8\%) patients went first to an MTS/RTS; leaving 61 patients (19.3\%) who went first to local/district hospitals (Table 2). A further 108 (34.2\%) were transferred indirectly to SCIU, from one of these other initial destinations, less than $60 \%$ transferred within $24 \mathrm{~h}$ from time of injury $(n=64,59.2 \%)$. Almost $30 \% \quad(n=93$, 29.4\%) of all patients remained in an MTS as their definitive hospital, 69 (74.2\%) had been admitted directly from the injury scene. A further $11(1.8 \%)$ were transferred in from an RTS and 13 (13.9\%) from local/district hospitals.

Analysing the GIS data of injury incident locations relative to the proximity to hospital types, we found over half $(53 \%, n=168)$ of all patients were injured within 60 min road travel from an SCIU, yet only $28.6 \%$ of these $(n=48)$ were directly transferred to SCIU. Of the remaining patients injured within the 60 -min radius, less than half $(48 \%, n=76)$ were first transferred to an MTS; $22(14 \%)$ first taken to an RTS. For $40 \%(n=125)$ of all patients the injury incident location was outside the 60 min travel radius of any MTS/SCIU, yet $20 \%$ went directly to an MTS and 20\% to SCIU.

Table 2 shows GIS calculated summary of road travel distances and times calculated from injury incident locations to first hospitals, nearest SCIU and trauma centre by class of first hospital, analysing separately $26(8.2 \%)$ patients who arrived by air-ambulance to their first hospital. For this group, Table 2 shows the actual times and distances ('direct' calculations) using hospital admission times and GIS data, also using GIS data to provide the 'on road' scenarios, had these patients travelled instead by road.

Differences between the first and second last column above indicate movement between hospital classes, for patients transferred from first to definitive hospitals $(n=$ 135, 42.7\%). For this transferred group, the median (IQR) time from first to definitive hospital admission was 11.7(38.5) hours; the mean (SD) was 105.7(314.3) hours. Of 193 patients admitted definitively to SCIU, those arriving indirectly, took median (IQR) of 10.5 (38.3) hours, and a mean (SD) of 112.7 (344.4) hours.

For patients not taken directly to a SCIU or an MTS but instead taken first to a local/district hospital $(n=61)$, the additional median (IQR) difference in travel times they would have had to make to reach an MTS would have been 79.9 (218.9) minutes; the mean (SD) 133.4 (130) minutes. Almost half $(n=28,46 \%)$ could have reached their closest MTS hospital by adding less than $30 \mathrm{~min}$ to their journey (median (IQR) 14.5(12.7) minutes). 
Table 2 Distances and times to first hospital from injury location GIS, by mode of transport

\begin{tabular}{|c|c|c|c|c|c|}
\hline $\begin{array}{l}\text { Hospital } \\
\text { Class }\end{array}$ & $\begin{array}{l}\text { First } \\
\text { Hospital } \\
\text { n (\%) }\end{array}$ & $\begin{array}{l}\text { Distance }(\mathrm{km}) \text { to first } \\
\text { hospital } \\
\text { Median (IQR) }\end{array}$ & $\begin{array}{l}\text { Time (mins) to first } \\
\text { hospital } \\
\text { Median (IQR) }\end{array}$ & $\begin{array}{l}\text { Definitive } \\
\text { Hospital } \\
\mathrm{n}(\%)\end{array}$ & $\begin{array}{l}\text { Time (hrs) to definitive } \\
\text { hospital }^{\mathrm{a}} \\
\text { Median (IQR) }^{\text {(IQR }}\end{array}$ \\
\hline \multicolumn{6}{|c|}{ Travelled by road ambulance - GIS calculated } \\
\hline SCIU & $67(23.1)$ & $20.3(72.7)$ & $27.6(51.6)$ & $170(58.6)$ & $12.6(39.9)$ \\
\hline MTS & $116(40.0)$ & $7.7(9.9)$ & $15.6(11.4)$ & $90(31.0)$ & $23.3(43.6)$ \\
\hline RTS & $46(15.8)$ & $13.4(29.5)$ & $18.0(23.1)$ & $17(5.9)$ & $19.9(44.4)$ \\
\hline Local & $61(21.0)$ & $8.7(27)$ & $12.4(19.5)$ & $13(4.5)$ & $2.9(0)$ \\
\hline Total & 290 & $9.7(20.0)$ & $16(17.8)$ & 290 & $14.4(42.9)$ \\
\hline \multicolumn{6}{|c|}{ Travelled by air ambulance - direct distances/ recorded times } \\
\hline SCIU & $18(69.2)$ & $120(141.9)$ & $176(279)$ & $23(88.5)$ & $8.9(5.2)$ \\
\hline MTS & $7(26.9)$ & $78.4(34.8)$ & $153(33)$ & $3(11.5)$ & N/A \\
\hline RTS & $1(3.8)$ & $217.3(0)$ & $261(0)$ & N/A & N/A \\
\hline \multicolumn{6}{|c|}{ Travelled by air ambulance - if had travelled by road (not adjusted for 'on scene' time) } \\
\hline SCIU & $18(69.2)$ & $151.2(184.7)$ & $111.7(102.9)$ & N/A & $23(88.5)$ \\
\hline MTS & $7(26.9)$ & $93.4(58.8)$ & $68.2(47.5)$ & N/A & $3(11.5)$ \\
\hline RTS & $1(3.8)$ & $268.3(0)$ & $185.5(0)$ & N/A & N/A \\
\hline Total & 26 & $122.8(133.2)$ & $168.5(100.2)$ & $\mathrm{N} / \mathrm{A}$ & 26 \\
\hline
\end{tabular}

${ }^{a}$ Calculated as hours from ambulance pick up (date/time) to admission (date/time) at definitive hospital

\section{Time to surgery}

Almost two-thirds $(n=194,61.4 \%)$ had surgery during acute care admissions; around two-thirds of these had surgery performed at SCIU $(n=131,67.5 \%)$. Additionally, $56(28.9 \%)$ received surgery at an MTS, 7 (3.6\%) at an RTS.

Times from ambulance call to surgery were available for 98 (51\%) patients; 47 (47.9\%) of whom were transferred directly from injury scene to SCIU and had surgery within median (IQR) of 12.9 (7.9) hours. This was more rapid than for patients transferred indirectly to SCIU (from MTS/RTS/local hospitals), who had surgery within median (IQR) of 19.5 (18.9) hours. Patients transferred directly from injury location to MTS and who surgery there, were operated within a median (IQR) of 21.8 (115.2) hours.

Comparing times to admission to hospitals where operations took place for the surgery group of 194 patients, Table 3 compares times to surgical hospital admission for the 98 for whom operation times were available with times to surgical hospital admission for the other 96 patients, as well as times to surgery where available. Interhospital transfers lengthened times to surgery; direct transfers received earlier operative intervention (median (IQR) 12.9(7.9) hours), compared with patients transferred indirectly to specialist spinal cord injury unit (median (IQR) 19.5(18.9) hours).

Factors influencing triage pattern to SCIU

The multinomial logistic regression model (Table 4) displays the RRR of various exposure variables to triage patterns; with direct SCIU admission as the base outcome category to no SCIU admission, then indirect SCIU admission. Where the nearest SCIU was within 60 min road travel from the injury incident the likelihood of no SCIU admission was significantly reduced (RRR $0.281, p=0.003,95 \%$ CI $0.123-0.646)$. The relative risk of indirect SCIU transfer was somewhat lower (RRR 0.511) than no SCIU. Patients with two or more concurrent traumatic injuries were 5.2 times more likely to experience indirect (rather than direct) transfer to SCIU (RRR 5.18, $p=0.002$ ). Patients with lower injury severity (ICISS $0.95-1.00$ ) were around 10 times more likely to have no admission to SCIU than direct transfer compared to patients with higher injury severity (ICISS $<0.7$ ), (RRR 10.1, $p=0.03$, 95\% CI 1.194-85.885). Patients without any completeness of injury coded were significantly more likely to experience no SCIU admission than direct SCIU admission (than patients coded as a 'complete' or 'incomplete' injury). Each year older for patients with acute TSCI increased the likelihood of not being admitted to a SCIU at all in the acute admission by $2 \%$ per year $(p=0.032)$. Table 4 displays the regression estimates for the entire cohort.

\section{Triage patterns influencing complication risk}

The potential impact of triage patterns on the risk of experiencing inpatient complications for patients with acute TSCI was assessed and is shown in Table 5. Patients experiencing indirect transfer to SCIU had an increased risk of developing inpatient hospital complications compared with patients transferred 
Table 3 First hospital, location of surgery and timing to surgery (median [IQR]) post injury

\begin{tabular}{|c|c|c|c|c|}
\hline Hospital Class & $\begin{array}{l}\text { As First hospital } \\
\text { n (\%) }\end{array}$ & $\begin{array}{l}\text { As Surgical Hospital } \\
\text { n (\%) }\end{array}$ & $\begin{array}{l}\text { Time to surgery } \\
\text { median (IQR) } \\
\text { (by surgical hospital class) }\end{array}$ & $\begin{array}{l}\text { Time (hrs) to surgical hospital admission } \\
\text { median (IQR) }\end{array}$ \\
\hline \multicolumn{5}{|c|}{ Time to surgery available $(n=98)$} \\
\hline SCIU & $47(47.9)$ & $90(91.8)$ & $15.2(10.9)$ & $6.7(7.3)$ \\
\hline MTS & $31(31.6)$ & $7(7.1)$ & $21.8(23.3)$ & $1.4(0.5)$ \\
\hline RTS & $8(8.2)$ & $1(1.0)$ & $12.7(0)$ & $1.4(0)$ \\
\hline Local & $12(12.2)$ & 0 & NA & NA \\
\hline Total & 98 & 98 & $15.2(11.2)$ & $6.1(7.2)$ \\
\hline \multicolumn{5}{|c|}{ Time to surgery not available $(n=96)$} \\
\hline SCIU & $18(18.7)$ & $41(42.7)$ & NA & $8.1(9.4)$ \\
\hline MTS & $45(46.9)$ & $49(51.0)$ & NA & $1.4(8.5)$ \\
\hline RTS & $20(20.8)$ & $6(6.3)$ & NA & $1.0(0.8)$ \\
\hline Local & $13(13.5)$ & 0 & NA & 0 \\
\hline Total & 194 & 194 & NA & $3.9(10.2)$ \\
\hline
\end{tabular}

${ }^{a}$ from ambulance pick up time

directly to SCIU. Complete TSCI, additional comorbidities (CCI) and older age also increased the risks of developing inpatient complications.

\section{Discussion}

This study investigated the impact of geospatial variables on access to specialist care for patients with acute TSCI across NSW and revealed that despite over half of the patients being injured within a 60 -min road travel time of a SCIU, less than $30 \%$ of them experienced a direct SCIU admission. This is poor by international comparison; Cheng et al. [10] in Canada demonstrating $77 \%$ of patients with acute TSCI and within $40 \mathrm{~km}$ of a SCIU admitted directly to a specialist unit. In this study, patients transferred directly to a SCIU underwent earlier surgery (median (IQR) of $7.3(6 ; 19)$ hours) than patients with indirect admission to SCIU, who waited $10 \mathrm{~h}$ longer to have their surgery (median (IQR) 17.5 (11; 31) hours). For many patients, indirect admission places them outside the recommended time window for surgery of $\leq 24$ $\mathrm{h}$ after injury, and at greater risk for medical complications and compromised recovery [31].

As specialist health services, the SCIUs in NSW are located in areas of high population density, however, serve large geographical areas. Increased travel time between the incident location and SCIU reduces the likelihood of direct transfer, indicating lack of equitable access to specialist care from all areas of NSW. The fact that $70 \%$ of patients who were injured within $60 \mathrm{~min}$ of road travel to a SCIU did not experience direct transfer, suggests variations in clinical practice that leads to inequity in patient treatment. Further, almost one-fifth of patients were taken first to non-trauma designated hospitals $(n=$ $61,19.3 \%)$, consistent with previous research showing that despite recommended pathways for patients with TSCI in NSW [24] some acute trauma patients are still being triaged to non-trauma services [19]. Regional ambulance services may have different service and staffing capacity as well as geographical delivery demands compared with metropolitan services, which may impact on transfer decisions, however this was not evaluated in the current study.

Aeromedical retrieval offers reduced travel times for the regional or very remote patient, demonstrated by these findings, however, there are resource restraints to this mode of transport. Scenario modelling could demonstrate the impact of changing transport modes to patients for whom distances by road are impediments to timely acute care. The additional resource required to retrieve patients with acute TSCI aeromedically needs to be justified by comprehensive economic evaluation. The cost per mission was estimated in 2011 at between $\$ 9300$ and $\$ 19,000$ [32]; the cost benefit of such retrieval outlay over the long term costs of a TSCI has not been sufficiently explored in Australia. Our previous research has shown by using scenario modelling (without geospatial data) to optimise patient-care pathways by direct in comparison with indirect admissions to SCIU, significant health system cost reductions can be achieved [16].

Patients were less likely to experience direct transfer to SCIU when they had less severe spinal cord impairment, such as conus and cauda equina injury. This may be appropriate, however, increasing age also reduced the likelihood of direct transfer; and older patients are known to have higher risks of hospital complications and poorer outcomes with delayed intervention [8]. As surgical intervention may not have been appropriate in some older patients, we are unable to ascertain if there 
Table 4 Multinomial regression model - relative risk of exposure variables comparing Indirect and No transfer to SCIU, with reference of direct admission to SCIU

\begin{tabular}{|c|c|c|c|c|}
\hline Triage Patterns & $\mathrm{RRR}^{\mathrm{a}}$ & Std. Err & $P$-value & 95\% Confidence Interval \\
\hline Direct SCIU & \multicolumn{3}{|c|}{ (as base outcome for No SCIU) } & \\
\hline \multicolumn{5}{|l|}{ No SCIU } \\
\hline age (years) & 1.02 & 0.01 & 0.034 & $1.002-1.039$ \\
\hline $\mathrm{SCIU}>60 \mathrm{~min}$ & 0.281 & 0.119 & 0.003 & $0.123-0.646$ \\
\hline Female sex & 0.959 & 0.44 & 0.928 & $0.391-2.355$ \\
\hline \multicolumn{5}{|l|}{ Injury Mechanism } \\
\hline \multicolumn{5}{|l|}{ Other (reference) } \\
\hline Falls & 0.629 & 0.343 & 0.388 & $0.21-1.83$ \\
\hline Transport & 0.559 & 0.343 & 0.344 & $0.17-1.86$ \\
\hline Self-harm /Assault & 11.449 & 16.289 & 0.087 & $0.70-186.13$ \\
\hline \multicolumn{5}{|l|}{ Injury level } \\
\hline \multicolumn{5}{|l|}{ Cervical (reference) } \\
\hline Thoracic & 1.838 & 0.983 & 0.255 & $0.64-5.24$ \\
\hline Lumbar & 3.917 & 5.142 & 0.298 & $0.29-51.33$ \\
\hline \multicolumn{5}{|l|}{ Extent of spinal cord Injury } \\
\hline \multicolumn{5}{|l|}{ Not coded (reference) } \\
\hline Complete & 0.061 & 0.044 & $<0.001$ & $0.015-0.25$ \\
\hline Incomplete & 0.288 & 0.159 & 0.024 & $0.09-0.85$ \\
\hline Conus/cauda-equina & 0.108 & 0.136 & 0.077 & $0.01-1.27$ \\
\hline \multicolumn{5}{|l|}{ Arrival Mode } \\
\hline \multicolumn{5}{|l|}{ Missing (reference) } \\
\hline Road Ambulance & 8.139 & 6.273 & 0.007 & $1.79-36.86$ \\
\hline Air ambulance & 0.61 & 0.606 & 0.619 & $0.09-4.27$ \\
\hline \multicolumn{5}{|l|}{ ICISS Score } \\
\hline \multicolumn{5}{|l|}{$<0.7$ (base) } \\
\hline 0.7 to $<0.83$ & 0.696 & 0.471 & 0.592 & $0.18-2.62$ \\
\hline 0.83 to $<0.89$ & 1.558 & 1.154 & 0.55 & $0.36-6.66$ \\
\hline 0.89 to $<0.95$ & 2.275 & 1.929 & 0.332 & $0.43-11.99$ \\
\hline 0.95 to 1.00 & 10.125 & 11.045 & 0.034 & $1.19-85.88$ \\
\hline \multicolumn{5}{|l|}{ Multiple trauma } \\
\hline \multicolumn{5}{|l|}{0 (base) } \\
\hline One additional injury & 0.35 & 0.158 & 0.02 & $0.15-0.85$ \\
\hline Two or more & 0.942 & 0.503 & 0.911 & $0.33-2.68$ \\
\hline Direct SCIU & (as bas & Indirect S & & \\
\hline \multicolumn{5}{|l|}{ Indirect SCIU } \\
\hline Age (years) & 0.998 & 0.01 & 0.84 & $0.98-1.02$ \\
\hline $\mathrm{SCIU}>60 \mathrm{~min}$ & 0.511 & 0.22 & 0.11 & $0.22-1.17$ \\
\hline Female sex & 0.96 & 0.45 & 0.93 & $0.38-2.43$ \\
\hline \multicolumn{5}{|l|}{ Injury Mechanism } \\
\hline \multicolumn{5}{|l|}{ Other (reference) } \\
\hline Falls & 0.51 & 0.28 & 0.22 & $0.17-1.49$ \\
\hline Transport & 0.56 & 0.34 & 0.34 & $0.17-1.84$ \\
\hline Self-harm/Assault & 9.02 & 12.77 & 0.12 & $0.56-144.74$ \\
\hline
\end{tabular}


Table 4 Multinomial regression model - relative risk of exposure variables comparing Indirect and No transfer to SCIU, with reference of direct admission to SCIU (Continued)

\begin{tabular}{|c|c|c|c|c|}
\hline Triage Patterns & $\mathrm{RRR}^{\mathrm{a}}$ & Std. Err & $P$-value & 95\% Confidence Interval \\
\hline \multicolumn{5}{|l|}{ Injury level } \\
\hline \multicolumn{5}{|l|}{ Cervical (reference) } \\
\hline Thoracic & 0.61 & 0.32 & 0.35 & $0.22-1.69$ \\
\hline Lumbar & 0.23 & 0.27 & 0.22 & $0.02-2.48$ \\
\hline \multicolumn{5}{|l|}{ Extent of Injury } \\
\hline \multicolumn{5}{|l|}{ Missing (reference) } \\
\hline Complete & 1.774 & 1.21 & 0.40 & $0.46-6.77$ \\
\hline Incomplete & 1.625 & 1.03 & 0.44 & $0.47-5.62$ \\
\hline Conus/cauda-equina & 0.502 & 0.59 & 0.56 & $0.05-5.01$ \\
\hline \multicolumn{5}{|l|}{ Arrival Mode } \\
\hline \multicolumn{5}{|l|}{ Other (reference) } \\
\hline Road ambulance & 20.148 & 18.13 & 0.001 & $3.45-117.52$ \\
\hline Air ambulance & 1.768 & 1.84 & 0.58 & $0.23-13.55$ \\
\hline \multicolumn{5}{|l|}{ ICISS Score } \\
\hline \multicolumn{5}{|l|}{$<0.7$ (reference) } \\
\hline 0.7 to $<0.83$ & 2.04 & 1.52 & 0.34 & $0.47-8.79$ \\
\hline 0.83 to $<0.89$ & 9.98 & 8.14 & 0.005 & $2.02-49.38$ \\
\hline 0.89 to $<0.95$ & 18.69 & 17.09 & 0.001 & $3.11-112.25$ \\
\hline 0.95 to 1.00 & 33.87 & 39.64 & $<0.001$ & $24.14-58.76$ \\
\hline \multicolumn{5}{|l|}{ Multiple trauma } \\
\hline \multicolumn{5}{|l|}{0 (reference) } \\
\hline One additional injury & 0.65 & 0.29 & 0.35 & $0.26-1.59$ \\
\hline Two or more & 5.18 & 2.77 & 0.002 & $1.82-14.75$ \\
\hline
\end{tabular}

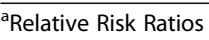

had been a discussion with the SCIU regarding the appropriateness of transfer to the Specialist Unit. It would seem likely that the combination of an incomplete spinal cord injury and increasing age represents the central cord syndrome group (although this was not specifically identified in this study). This group typically present after minor falls and may not be immediately recognised as TSCI [33], so may have missed being treated according to the transfer guidelines.

\section{Limitations}

This study had several limitations. As we required geographic variables, we were unable to include the complete cohort of patients with acute incident TSCI identified across the study in this analysis. Therefore, a selection bias was possible, given omission of certain patients. This may incorrectly estimate the proportion of patients who were correctly admitted to specialist care in a timely manner. The missingness of GIS data may be explained by the transition from paper to electronic NSW Ambulance data systems, however in the provision of data, the Ambulance Service was unable to offer further information on this. We therefore made the decision to analyse all available data and treat missing data as 'random', for the purposes of informing future cohorts. As electronic data collections are improved, it is likely that this limitation will be reduced in future. We did, however, evaluate the cohort of patients not included across key variables (age, injury mechanism and completeness of injury), and noted that patients not included were found to have similar characteristics across these variables., This was therefore not deemed significantly impactful on our findings.

\section{Conclusion}

This study used geospatial methods to analyse pathways of care for patients with acute TSCI in NSW, who received care in a SCIU by either direct or indirect admission and has highlighted specific areas for optimisation on a health system level. Our finding that only $30 \%$ of patients who sustained injuries within a 60-min travel radius to a SCIU were directly admitted, is significantly lower than international comparisons and advocates improvement in early transport pathways to TSCI care. 
Table 5 Triage pattern impact on risk of developing a medical complication as an inpatient

\begin{tabular}{|c|c|c|c|c|}
\hline Any complication ${ }^{a}$ & Odds Ratio & Std.Err & $P$-value & 95\% Conf. Interval \\
\hline \multicolumn{5}{|l|}{ Triage Patterns } \\
\hline Direct SCIU & 1.392 & 0.492 & 0.35 & $0.696-2.783$ \\
\hline Indirect SCIU & 3.243 & 1.113 & 0.001 & $1.656-6.353$ \\
\hline \multicolumn{5}{|l|}{ No SCIU (reference) } \\
\hline \multicolumn{5}{|l|}{ Demographic } \\
\hline Female sex & 1.122 & 0.357 & 0.718 & $0.601-2.095$ \\
\hline Age (years) & 1.011 & 0.006 & 0.050 & $0.999-1.023$ \\
\hline \multicolumn{5}{|l|}{ Extent of TSCI } \\
\hline Complete & 6.917 & 3.672 & $<0.001$ & $2.443-19.579$ \\
\hline Incomplete & 1.447 & 0.536 & 0.319 & $0.7-2.989$ \\
\hline Conus/cauda-equina & 1.57 & 0.685 & 0.301 & $0.668-3.692$ \\
\hline \multicolumn{5}{|l|}{ Missing (reference) } \\
\hline \multicolumn{5}{|l|}{ Charlson Index } \\
\hline \multicolumn{5}{|c|}{ No comorbid disease (ref) } \\
\hline 1 additional & 1.468 & 0.57 & 0.323 & $0.686-3.143$ \\
\hline $2+$ additional & 3.268 & 1.302 & 0.003 & $1.497-7.135$ \\
\hline \multicolumn{5}{|l|}{ Multiple Trauma } \\
\hline \multicolumn{5}{|c|}{ No additional injuries (ref) } \\
\hline 1 additional injury & 1.818 & 0.609 & 0.075 & $0.942-3.506$ \\
\hline 2+ additional injuries & 1.15 & 0.367 & 0.661 & $0.615-2.149$ \\
\hline \multicolumn{5}{|l|}{ Injury Severity (ICISS) } \\
\hline 0.7 to $<0.83$ & 0.222 & 0.107 & 0.002 & $0.086-0.572$ \\
\hline 0.83 to $<0.89$ & 0.085 & 0.043 & $<0.001$ & $0.032-0.23$ \\
\hline 0.89 to $<0.95$ & 0.139 & 0.07 & $<0.001$ & $0.051-0.374$ \\
\hline 0.95 to 1.00 & 0.113 & 0.063 & $<0.001$ & $0.038-0.335$ \\
\hline
\end{tabular}

ancludes pressure injuries, urinary tract infections/complications, respiratory infections/complications, deep vein thrombosis and pulmonary embolus

Regardless of injury incident location, it is evident that there are transport modes and decisions can achieve early and direct SCIU admission with timely surgery. These findings complement previous research showing cost savings and reduced secondary complications achievable by streamlining care pathways [16] for patients with TSCI. Evidence informed policy in health service optimisations can provide timely and definitive surgical treatment for those patients suffering an acute TSCI, leading to improved neurological outcomes and reduced secondary complications and mortality. These findings are being currently utilised by the SSCIS to encourage evidence informed improvement of the health system in NSW for this acutely unwell patient population.

\section{Abbreviations}

APDC: Admitted Patient Data Collection; CCl: Charlson comorbidity index; GIS: Geographic information system; ICD10-AM: International Classification of Diseases, 10th version, Australian Modification; ICISS: International Classification Injury Severity Score; MTS: Major trauma service; NSW: New South Wales; RRR: Relative Risk Ratios; RTS: Regional trauma service;
SA: Statistical area; SCIU: Spinal cord injury unit; SSCIS: State Spinal Cord Injury Service; TSCI: Traumatic spinal cord injury; TBI: Traumatic brain injury

\section{Supplementary Information}

The online version contains supplementary material available at https://doi. org/10.1186/s12913-021-06235-4.

Additional file 1: Appendix 1. Datasets and variables used

\section{Acknowledgements}

The authors acknowledge the statistical advice provided by Professor Jeff Meyers at www.theanalysisfactor.com, and thank Professor Roderick McClure for his recommendations on the study reporting.

\section{Authors' contributions}

LNS conceived of this project and analysed and interpreted the patient data regarding the health services modelling. SRW analysed the data pertaining to geospatial mapping. DW and MK produced the map and provided interpretation to its meaning. CC and VKN provided insight and written evidence regarding comparison of study findings with their Canadian research. APJ, JB, RES, JW edited the manuscript with medical insight interpreting the pre-hospital, trauma, and surgical management of patients with TSCI. BPV analysed the costs data. LNS, DW, MK, CC, VKN, APJ, JB, RES, BPV and JW critically revised and approved the final manuscript. The author(s) read and approved the final manuscript. 


\section{Funding}

LNS was funded by icare ${ }^{T M}$ for the duration of this research. BPV was funded on a doctoral scholarship for the duration of this research. The funder critically reviewed and approved the study protocol developed for this research. The foundational study for this body of work was awarded to JM as funding by NHMRC (APP1037258)

\section{Availability of data and materials}

The data that support the findings of this study are available from the Centre for Health Record Linkage, New South Wales, Australia, but restrictions apply to the availability of these data, which were used under license for the current study, and so are not publicly available.

\section{Declarations}

\section{Ethics approval and consent to participate}

The NSW Population and Health Services Research Ethics Committee (Cancer Institute NSW) approved this project (AU RED Reference: HREC/16/CIPHS/19; Cancer Institute NSW reference number: 2016/07/647). Data custodian approvals were provided by Dr. Lee Taylor for the APDC, Dr. Rosemary Carney for the NSW Ambulance dataset, Ms. Amanda lanna for the RBDM dataset and Mr. Alfa D'Amato for the NSW-DNR dataset.

\section{Consent for publication}

Not applicable as this project used de-identified administrative data.

\section{Competing interests}

Dr. Lisa N. Sharwood is an Editorial Board Member of the BMC Health Services Research journal. The conducted work or its submission was not influenced by this role. No other authors declare any competing interests.

\section{Author details}

'Sydney Medical School, Faculty of Medicine and Health, University of Sydney, Reserve Road, St Leonards, NSW 2065, Australia. ${ }^{2}$ University of New South Wales, Faculty of Medicine and Health, NSW Black Dog Institute, Sydney, Australia. ${ }^{3}$ University of Technology Sydney, Faculty of Engineering, Sydney, NSW, Australia. ${ }^{4}$ Monash University, Department of Epidemiology and Preventive Medicine, Melbourne, VIC, Australia. ${ }^{5}$ University of Western Australia, (M706), 35 Stirling Highway, Perth 6009, Australia. ${ }^{6}$ John Walsh Centre for Rehabilitation Research, Kolling Institute, Northern Clinical School, Faculty of Medicine and Health, University of Sydney, Reserve Road, St Leonards, NSW 2065, Australia. ${ }^{7}$ Praxis Spinal Cord Institute, 6400-818 W 10th Ave, Vancouver, BC V5Z 1M9, Canada. ${ }^{8}$ Royal North Shore Hospital, Trauma Department, Reserve Road, St Leonards, NSW 2065, Australia. ${ }^{9}$ Faculty of Medicine and Health, University of Sydney, Sydney, Australia. ${ }^{10}$ Royal North Shore Hospital, Neurosurgery, St Leonards, NSW 2065, Australia. ${ }^{11}$ Prince of Wales Hospital, Spinal Cord Injury Unit, Randwick, NSW 2033, Australia. ${ }^{12}$ Australian Institute of Robotic Orthopaedics, Perth, Western Australia, Australia. ${ }^{13}$ John Walsh Centre for Rehabilitation Research, Kolling Institute, Reserve Road, St Leonards, NSW 2065, Australia. ${ }^{14}$ Agency for Clinical Innovation, NSW Health, Reserve Road, St Leonards, NSW 2065, Australia.

\section{Received: 22 September 2020 Accepted: 2 March 2021}

\section{Published online: 01 April 2021}

\section{References}

1. Atkins D, Noonan V, Santos A, Lewis R, Fehlings M, Burns A, et al. Secondary complications in $\mathrm{SCl}$ across the continuum: using operations research to predict the impact and optimize management strategies. Topics Spinal Cord Rehabil. 2012;18(1):57-66. https://doi.org/10.1310/sci1801-57.

2. Craig A, Guest R, Tran Y, Middleton J. Depressive mood in adults with spinal cord injury as they transition from an inpatient to a community setting: secondary analyses from a clinical trial. Spinal Cord. 2017;55(10):926-34. https://doi.org/10.1038/sc.2017.41

3. Craig A, Nicholson Perry K, Guest R, Tran Y, Dezarnaulds A, Hales A, et al The occurrence of psychological disorders and co-morbidities following spinal cord injury. Arch Phys Med Rehabil. 2015;96(8):1426-34. https://doi. org/10.1016/j.apmr.2015.02.027

4. Access Economics Pty Ltd. The economic cost of spinal cord injury and traumatic brain injury in Australia; 2009. p. 1-116.
5. Munce S, Wodchis W, Guilcher S, Couris C, Verrier M, Fung K, et al. Direct costs of adult traumatic spinal cord injury in Ontario. Spinal Cord. 2013; 51(1):64-9. https://doi.org/10.1038/sc.2012.81.

6. Consortium for Spinal Cord Medicine. Early acute management in adults with spinal cord injury: a clinical practice guideline for healthcare professionals. J Spinal Cord Med. 2008;31(4):403-79.

7. Mac-Thiong J, Feldman D, Thompson C, Bourassa-Moreau E, Parent S. Does timing of surgery affect hospitalization costs and length of stay for acute care following a traumatic spinal cord injury? J Neurotrauma. 2012;29(18): 2816-22. https://doi.org/10.1089/neu.2012.2503.

8. Parent S, Barchi S, LeBreton M, Casha S, Fehlings M. The impact of specialized centers of care for spinal cord injury on length of stay, complications, and mortality: a systematic review of the literature. J Neurotrauma. 2011;28(8):1363-70. https://doi.org/10.1089/neu.2009.1151.

9. Sharwood L, Boufous S, Muecke S, Middleton J. Health Service Pathways Analysis as Evidence Base for Trauma Policy Change. Emerg Med. 2017;7(3). https://doi.org/10.4172/2165-7548.1000353.

10. Cheng CL, Noonan VK, Shurgold J, Chen J, Rivers CS, Hamedani HK, et al. Geomapping of Traumatic Spinal Cord Injury in Canada and Factors Related to Triage Pattern. J Neurotrauma. 2017;34(20):2856-66. https://doi.org/10.1 089/neu.2016.4929.

11. NSW Agency for Clinical Innovation. Evidence and utilisation of spinal cord injury services NSW: Evidence Series. 2020; SHPN (ACI) 190018(ISBN 978-176081-068-9).

12. Vulliamy P, Faulkner M, Kirkwood G, West A, O'Neill B, Griffiths MP, et al. Temporal and geographic patterns of stab injuries in young people: a retrospective cohort study from a UK major trauma Centre. BMJ Open. 2018; 8(10):e023114. https://doi.org/10.1136/bmjopen-2018-023114.

13. Brown JB, Kheng M, Carney NA, Rubiano AM, Puyana JC. Geographical disparity and traumatic brain injury in America: rural areas suffer poorer outcomes. J Neurosci Rural Pract. 2019;10(1):10-5. https://doi.org/10.4103/ jnrp.jnrp_310_18.

14. Auchincloss AH, Gebreab SY, Mair C, Diez Roux AV. A review of spatial methods in epidemiology, 2000-2010. Annu Rev Public Health. 2012;33(1): 107-22. https://doi.org/10.1146/annurev-publhealth-031811-124655.

15. Smedley WA, Stone KL, Brown A, Farley P, Griffin RL, Cox DB, et al. Use of helicopters for retrieval of trauma patients: a geospatial analysis. J Trauma Acute Care Surg. 2019;87(1):168-72. https://doi.org/10.1097/TA. 0000000000002318

16. Vaikuntam B, Middleton J, McElduff P, Pearse J, Walsh J, Cameron I, et al. Identifying Predictors of Higher Acute Care Costs for Patients With Traumatic Spinal Cord Injury and Modeling Acute Care Pathway Redesign. Spine (Phila Pa 1976). 2019;44(16):E974-83. https://doi.org/10.1097/BRS. 0000000000003021

17. Gomez D, Sarrami P, Singh H, Balogh Z, Dinh M, Hsu J. External benchmarking of trauma services in New South Wales: Risk-adjusted mortality after moderate to severe injury from 2012 to 2016. Injury. 2019; 50(1):178-85. https://doi.org/10.1016/j.injury.2018.09.037. Epub 2018 Sep 23.

18. Brown JB, Stassen NA, Cheng JD, Sangosanya AT, Bankey PE, Gestring ML. Trauma center designation correlates with functional independence after severe but not moderate traumatic brain injury. J Trauma. 2010;69(2):263-9. https://doi.org/10.1097/TA.0b013e3181e5d72e.

19. Doumouras AG, Haas B, Gomez D, de Mestral C, Boyes DM, Morrison LJ, et al. The impact of distance on triage to trauma center care in an urban trauma system. Prehosp Emerg Care. 2012;16(4):456-62. https://doi.org/10.31 09/10903127.2012.695431.

20. Middleton J, Sharwood L, Cameron P, Middleton P, Harrison J, McClure R, et al. Right care, right time, right place: improving outcomes for people with spinal cord injury through early access to intervention and improved access to specialised care: study protocol. BMC Health Serv Res. 2014; 14:600.

21. Australian Bureau of Statistics. Australian Demographic Statistics. Canberra: Australian Bureau of Statistics; 2016

22. Lundy DW, Harvey EJ, Jahangir AA, Leighton RK. Trauma systems in North America. OTA Int. 2019;2(S1).

23. Gomez D, Larsen K, Burns BJ, Dinh M, Hsu J. Optimizing access and configuration of trauma centre care in New South Wales. Injury. 2019;50(5): 1105-10. https://doi.org/10.1016/j.injury.2019.02.018. Epub 2019 Feb 27.

24. NSW Health. NSW Critical Care Tertiary Referral Networks and Transfer of Care (ADULTS). Policy Directive. 2018:PD2018 011(Agency for Clinical Innovation):1-37. 
25. Australian Consortium for Classification Development. The international statistical classification of diseases and related health problems, tenth revision, australian modification (ICD-10-AM/ACHI/ACS). 10th ed. Darlinghurst: Independent Hospital Pricing Authority; 2017.

26. Vaikuntam BP, Middleton JW, McElduff P, Pearse J, Walsh J, Cameron ID, et al. Assessing the impact of care pathways on potentially preventable complications and costs for spinal trauma patients: a data linkage study. BMJ Open. 2018;8(11):e023785. https://doi.org/10.1136/bmjopen-2018-023785.

27. Kwak C, Clayton-Matthews A. Multinomial Logistic Regression. Nurs Res. 2002;51(6):404-10. https://doi.org/10.1097/00006199-200211000-00009.

28. STATACorp. Stata Statistical Software. 2017; Version 15.1 IC.

29. Gedeborg R, Warner M, Chen LH, Gulliver P, Cryer C, Robitaille Y, et al. Internationally comparable diagnosis-specific survival probabilities for calculation of the ICD-10-based injury severity score. J Trauma Acute Care Surg. 2014;76(2):358-65. https://doi.org/10.1097/TA.0b013e3182a9cd31.

30. Australian Bureau of Statistics. Technical Paper - Socio-Economic Indexes for Areas (SEIFA); 2018. p. 2033.0.55.001

31. Dvorak MF, Noonan VK, Fallah N, Fisher CG, Finkelstein J, Kwon BK, et al. The influence of time from injury to surgery on motor recovery and length of hospital stay in acute traumatic spinal cord injury: an observational Canadian cohort study. J Neurotrauma. 2015;32(9):645-54. https://doi.org/1 0.1089/neu.2014.3632.

32. Taylor CB, Stevenson M, Jan S, Liu B, Tall G, Middleton PM, et al. An investigation into the cost, coverage and activities of helicopter emergency medical services in the state of New South Wales, Australia. Injury. 2011; 42(10):1088-94. https://doi.org/10.1016/j.injury.2011.02.013.

33. Middleton P, Davies S, Anand S, Marial O, Reinten-Reynolds T, Middleton J. The prehospital epidemiology and management of spinal cord injuries in NSW: 2004-2008. Injury. 2012;43(4):480-5. https://doi.org/10.1016/j.injury.2 011.12.010.

\section{Publisher's Note}

Springer Nature remains neutral with regard to jurisdictional claims in published maps and institutional affiliations.

Ready to submit your research? Choose BMC and benefit from:

- fast, convenient online submission

- thorough peer review by experienced researchers in your field

- rapid publication on acceptance

- support for research data, including large and complex data types

- gold Open Access which fosters wider collaboration and increased citations

- maximum visibility for your research: over $100 \mathrm{M}$ website views per year

At $\mathrm{BMC}$, research is always in progress.

Learn more biomedcentral.com/submissions 